\title{
Development and assessment of competency-based neurotrauma course curriculum for international neurosurgery residents and neurosurgeons
}

\author{
Sergio A. Calero-Martinez, MD, ${ }^{1,2}$ Christian Matula, MD, ${ }^{3}$ Aurelia Peraud, MD, PhD, ${ }^{4}$ \\ Francesco Biroli, MD, ${ }^{5}$ José Fernández-Alén, MD, PhD, ${ }^{6}$ Michael Bierschneider, MD, ${ }^{7}$ \\ Michael Cunningham, PhD, ${ }^{8}$ Gregory W. J. Hawryluk, MD, PhD, ${ }^{9}$ Maya Babu, MD, MBA, ${ }^{10}$ \\ M. Ross Bullock, MD, PhD,11 and Andrés M. Rubiano, MD $1,12,13$ \\ ${ }^{1}$ Meditech Foundation, Cali, Colombia; ${ }^{2}$ Clemenshospital Münster, Germany; ${ }^{3}$ Department of Neurosurgery, Medical University \\ of Vienna, Austria; ${ }^{4}$ University Hospital of Ulm, Germany; ${ }^{5}$ Fondazione per la Ricerca Ospedale Maggiore, Bergamo, Italy; \\ ${ }^{6}$ Hospital 12 de Octubre, Madrid, Spain; ${ }^{7 B G}$ Unfallklinik Murnau, Germany; ${ }^{8} \mathrm{AO}$ Education Institute, AO Foundation, Dubendorf, \\ Switzerland; 9University of Manitoba, Winnipeg, Manitoba, Canada; ${ }^{10 M a s s a c h u s e t t s ~ G e n e r a l ~ H o s p i t a l, ~ B o s t o n, ~ M a s s a c h u s e t t s ; ~}$ \\ ${ }^{11}$ University of Miami, Florida; ${ }^{12}$ Universidad El Bosque, Bogota, Colombia; and ${ }^{13}$ Global Neuro Foundation, Davos, Switzerland
}

OBJECTIVE Traumatic brain injuries (TBIs) are a significant disease burden worldwide. It is imperative to improve neurosurgeons' training during and after their medical residency with appropriate neurotrauma competencies. Unfortunately, the development of these competencies during neurosurgeons' careers and in daily practice is very heterogeneous. This article aimed to describe the development and evaluation of a competency-based international course curriculum designed to address a broad spectrum of needs for taking care of patients with neurotrauma with basic and advanced interventions in different scenarios around the world.

METHODS A committee of 5 academic neurosurgeons was involved in the task of building this course curriculum. The process started with the identification of the problems to be addressed and the subsequent performance needed. After this, competencies were defined. In the final phase, educational activities were designed to achieve the intended learning outcomes. In the end, the entire process resulted in competency and outcomes-based education strategy, including a definition of all learning activities and learning outcomes (curriculum), that can be integrated with a faculty development process, including training. Further development was completed by 4 additional academic neurosurgeons supported by a curriculum developer specialist and a project manager. After the development of the course curriculum, template programs were developed with core and optional content defined for implementation and evaluation.

RESULTS The content of the course curriculum is divided into essentials and advanced concepts and interventions in neurotrauma care. A mixed sample of 1583 neurosurgeons and neurosurgery residents attending 36 continuing medical education activities in 30 different cities around the world evaluated the course. The average satisfaction was $97 \%$. The average usefulness score was 4.2, according to the Likert scale.

CONCLUSIONS An international competency-based course curriculum is an option for creating a well-accepted neurotrauma educational process designed to address a broad spectrum of needs that a neurotrauma practitioner faces during the basic and advanced care of patients in different regions of the world. This process may also be applied to other areas of the neurosurgical knowledge spectrum. Moreover, this process allows worldwide standardization of knowledge requirements and competencies, such that training may be better benchmarked between countries regardless of their income level.

https://thejns.org/doi/abs/10.3171/2019.12.FOCUS19850

KEYWORDS neurotrauma; education; competence-based; course; curriculum; international

$\mathrm{T}$ RAUMATIC brain injuries (TBIs) are a significant disease burden worldwide. The WHO considers that TBI establishes notable public health and socioeconomic issues, considered as a silent epidemic because of its related morbidity and mortality. ${ }^{26}$ According to the actual evidence, nearly 69 million (95\% CI 64-74 million) individuals are estimated to suffer TBI from all causes each year, with a greater impact in low- and middle-income countries (LMIC). ${ }^{11,25}$

The neurotrauma-affected population is in general

ABBREVIATIONS CME = continuing medical education; LMIC = low- and middle-income countries; $\mathrm{TBI}=$ traumatic brain injury .

SUBMITTED November 1, 2019. ACCEPTED December 31, 2019.

INCLUDE WHEN CITING DOI: 10.3171/2019.12.FOCUS19850. 
described as young adult pedestrians, cyclists, or motorcyclists, and this same age range is associated with other causes of neurotrauma like armed violence by assault and gunshot injuries. ${ }^{7,24,32}$ Recently, neurotrauma epidemiology in Western countries has changed, showing an increase in the mean age, reflected by the increase in falls among elderly patients.

For the aforementioned reasons, it is imperative to improve neurosurgeons' training during and after their medical residency with appropriate neurotrauma competencies. Unfortunately, the development of these competencies during a neurosurgeon's career and in daily practice is very heterogeneous due to several factors like low volume of neurotrauma cases in the training/practice centers, program focus different than neurotrauma (i.e., spine, vascular, cranial base, functional), and instructor's bias over different personal preferences. ${ }^{15,20,31}$ Furthermore, there is the lack of resources and equipment present in centers that deal daily with neurotrauma, for instance, in LMIC. ${ }^{19,34}$ Those issues generate a problem at some stage of the patient management process.

One approach to solve those issues can be the development of a structured neurotrauma course curriculum. The AO Education Institute defines a curriculum as a statement of the intended aims and objectives, content, experiences, outcomes, and processes of an education program, including a description of the target audience, (modular) structure, instructional methods, as well as assessment strategies. ${ }^{8}$

The course curriculum sets out the competencies (knowledge, skills, attitudes, and behaviors) that the learner will achieve. It further specifies how it is delivered, implemented, and evaluated. Based on this routine curriculum, individual events (a set of activities) are designed (e.g., a course for residents, a webinar for experts) providing neurotrauma points of knowledge, attitudes, and skills, framed in the public health reality of a disease that affects millions of people and also identifying the necessities that each region could have, in particular at the worldwide level. Therefore, it is necessary to standardize these concepts and teach a new strategy in neurotrauma care through a competency-based course curriculum, including aspects of professionalism and communication skills. ${ }^{22,23}$

This article aims to describe the development and evaluation of such a competency-based international course curriculum designed to address a broad spectrum of needs for taking care of neurotrauma patients with basic and advanced interventions in different scenarios around the world.

\section{Methods}

\section{Team and Strategy}

The Global Neuro Foundation, as an independent association of academic neurosurgeons dedicated to the improvement of neurosurgical education at the global level (started as the AONeuro initiative of the AO Foundation), was interested in the development of a standardized international course curriculum for neurotrauma education worldwide. In 2014, a committee of 5 academic neuro- surgeons from Austria, Germany, Italy, and Spain was involved in the task of building this course curriculum based on a backward-planning strategy. This process started with the identification of the problems that must be addressed and the performance that these problems demand from the surgeon. After this initial phase, competencies or abilities were defined in order to describe what the healthcare professional must be able to do to address these problems. In the final phase and based on the concepts of competency-based education, educational activities were designed to achieve the intended learning outcomes.

At the end, the entire process resulted in a competency- and outcomes-based education strategy, including a definition of all learning activities and learning outcomes (curriculum), that can be integrated with a faculty development process, including training, to deliver the content by using the appropriate methods, resources (learning materials developed in response to needs), and the assessment and evaluation process for identifying needs and to track progress. After this initial step, further development was completed and 4 additional academic neurosurgeons from different regions of the world (Colombia, Canada, US, and Australia), supported by a curriculum development specialist (medical educator) and a project manager. On the date of submission of this article, a total of 9 neurosurgeons were involved.

\section{Curriculum Committee}

The course curriculum committee was responsible for developing and editing all content (cases), assessment question writing, video recording, simulation design, and implementation of practical exercises. The committee members were volunteer neurosurgeons receiving no payment for attending the face-to-face meetings. A total of 3 sessions of 2 days each was required to finish the whole process.

\section{Curriculum Development Process}

Neurosurgeons participated in the backward planning for the neurotrauma course curriculum over 3 years of development, between 2014 and 2017. The initial 12 patients' cases and clinical problems (Table 1) were identified and tailored according to the experience of the academic neurosurgeons teaching continuing medical education (CME) events all over the world. Personal communications from colleagues acting as educational events chairpersons in neurotrauma courses were included. In 2017 this step was updated and complemented or modified according to preand postcourse evaluations and according to new evidence in the specialized literature.

Additionally, the development of 10 competencies to approach patient and clinical problems was presented in a course (Table 2). After this step, proposed learning outcomes (objectives) related to each competency were organized as knowledge, skill, and desirable attitude learning points (see AONeuro Curricula). After the development of these objectives, the target audience was selected according to their level of knowledge as providers of healthcare for patients with neurotrauma. In the end, the intended audience was any neurosurgeon or neurosurgical trainee 
TABLE 1. Patients and clinical problems covered in the neurotrauma course

\begin{tabular}{|c|c|}
\hline 2016 & 2017 \\
\hline Brain injury & Brain injury \\
\hline Bleeding & Bleeding \\
\hline Contusion & Contusion \\
\hline \multirow[t]{4}{*}{ Swelling } & Swelling \\
\hline & Neurovascular injury \\
\hline & Brain hypoxia \\
\hline & Concussion \\
\hline Fractures & Fractures \\
\hline Depressed skull fracture & Depressed skull fracture \\
\hline Compound, linear, branched fractures & Compound, linear, branched fractures \\
\hline Skull base fracture & Skull base fracture \\
\hline \multirow[t]{2}{*}{ Craniocervical junction fracture } & Craniocervical junction fracture \\
\hline & Frontal sinus fracture \\
\hline ICP increase & ICP increase \\
\hline CSF leakage & CSF leakage \\
\hline Life-threatening issues & Life-threatening issues \\
\hline Depressed consciousness & Depressed consciousness \\
\hline Difficulty breathing & Difficulty breathing \\
\hline Low blood pressure & Low blood pressure \\
\hline Penetrating head injury & Penetrating head injury \\
\hline Circulation & Circulation \\
\hline Additional injuries (isolated trauma vs polytrauma) & Additional injuries (isolated trauma vs polytrauma) \\
\hline Technical problems & Technical problems (patient safety) \\
\hline Rescue chain & Rescue chain \\
\hline Timing of decisions and interventions & Timing of decisions and interventions \\
\hline \multirow[t]{2}{*}{ Pre-existing conditions (i.e., hypertension) } & Pre-existing conditions (i.e., hypertension, coagulopathy, medications) \\
\hline & Nonaccidental brain injury \\
\hline Organization/the system & Organization/the system \\
\hline Who manages the patient? & Who manages the patient? \\
\hline Referrals, specialists, etc. & Referrals, specialists, etc. \\
\hline Decision making & Decision making \\
\hline Availability of facilities & Availability of facilities \\
\hline Surgical, iatrogenic complications & Surgical, iatrogenic complications \\
\hline Identification, management, avoidance & Identification, management, avoidance \\
\hline \multirow[t]{2}{*}{ Control vital functions } & Control vital functions \\
\hline & Poor initial resuscitation \\
\hline Complications & Complications \\
\hline Hydrocephalus & Hydrocephalus \\
\hline Post-trauma epilepsy & Post-trauma epilepsy \\
\hline Long-term functional disability & Long-term functional disability \\
\hline Infection & Infection \\
\hline \multirow[t]{5}{*}{ Morphological problems, aesthetics } & Morphological problems, aesthetics \\
\hline & Neurovascular injuries \\
\hline & Pseudoaneurysm \\
\hline & Posttraumatic aneurysm \\
\hline & Trephined syndrome \\
\hline
\end{tabular}

ICP = intracranial pressure.

The problems updated in 2017 are marked in bold. 
TABLE 2. Competencies for the Global Neurotrauma Curriculum

\begin{tabular}{l}
\hline Perform basic assessment in an emergency situation \\
\hline Integrate into interdisciplinary management \\
Decide appropriate investigations, interpret the results, and react \\
appropriately \\
Select and perform operative procedures \\
\hline Select and perform nonoperative procedures \\
\hline Manage ICP \\
\hline Prevent, identify, and manage complications \\
\hline Organize rehabilitation transfer and follow-up \\
\hline Apply guidelines specific to neurotrauma \\
\hline Communicate with the patient, relatives, and colleagues \\
\hline
\end{tabular}

who provides care to injured patients from prehospital environments to intra- and posthospital care.

In a third face-to-face 2-day meeting, a new round of feedback from young academic neurotrauma experts from different regions was provided for new discussion and integration. During the whole process, educational content was developed for delivering and evaluating these $\mathrm{CME}$ activities, including a case library, teaching videos, assessment questions, reference materials, webinars, and teaching methods for present and future faculty. The final output documents were reviewed by senior academic neurosurgeons from the AONeuro Curriculum Development Group and then complemented after the internal transition by additional academic neurosurgeons of the Global Neuro Curriculum Development Group. For the statistical analysis, the averages of the total courses carried out for 5 years were used.

\section{Results}

A program structure for evaluation of the course curriculum was proposed, including a basic and an advanced template of courses based on a modular structure (Fig. 1). In 2017 the 2 courses were renamed as Essentials in Neurotrauma (basic) and Advanced Neurotrauma (advanced). After the development of the course curriculum, a mixed sample of 1583 neurosurgeons and neurosurgery residents attending $36 \mathrm{CME}$ activities in 30 different cities around the world evaluated the impact, as is shown in Fig. 2.

Every event was evaluated with a standard set of preand postevent assessment questions, including a Likert scale (scores range from 0.0 to 5.0) regarding the course curriculum content usefulness and the usability of this content for actual and future academic and CME activities and as part of the formal training programs in their countries of origin. The mean grade for the course curriculum content, including the delivery and dissemination strategies, was 4.2 (Fig. 3). The average satisfaction with the course curriculum content and the application (topics, delivery strategies, and evaluation) for CME neurotrauma activities and postgraduate training programs was $97 \%$, as is shown in Fig. 4.

\section{Discussion}

\section{Development of a Neurotrauma Course Curriculum}

The course curriculum development process we describe is consistent with previously published works re-
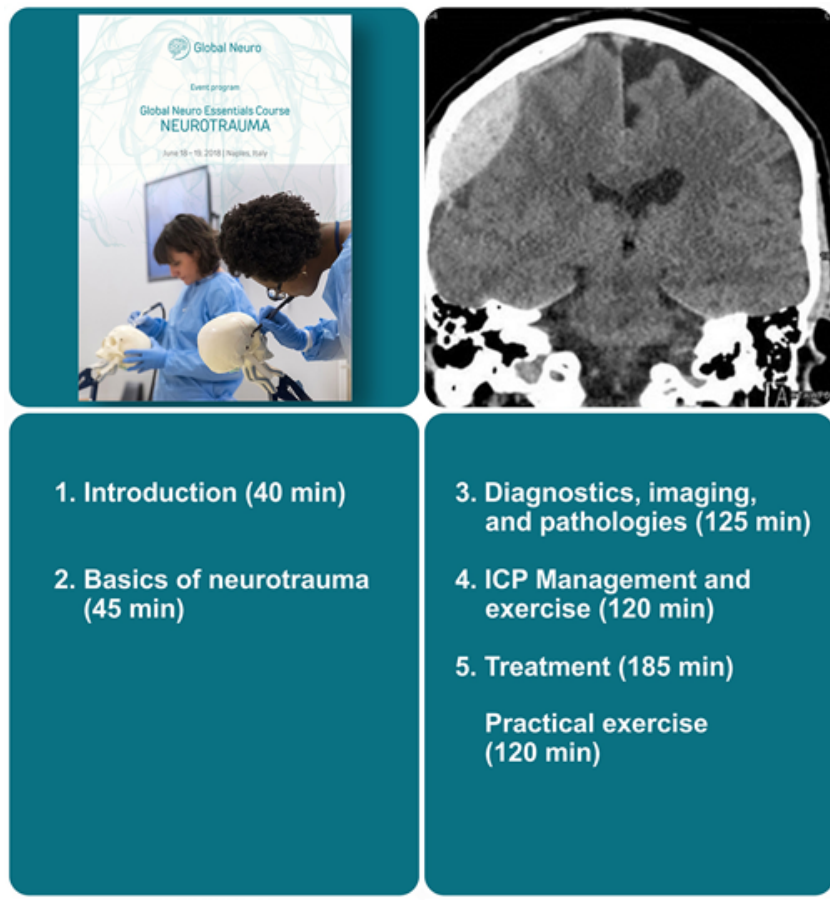
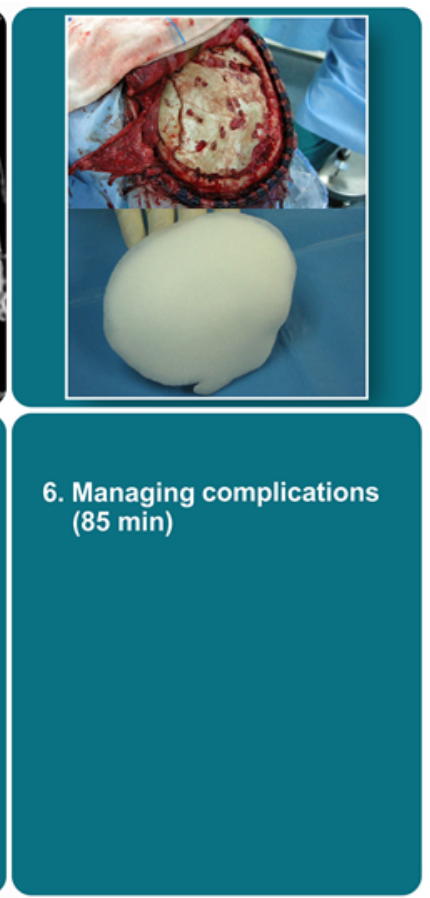

FIG. 1. Modular structure for neurotrauma courses. ICP = intracranial pressure. 


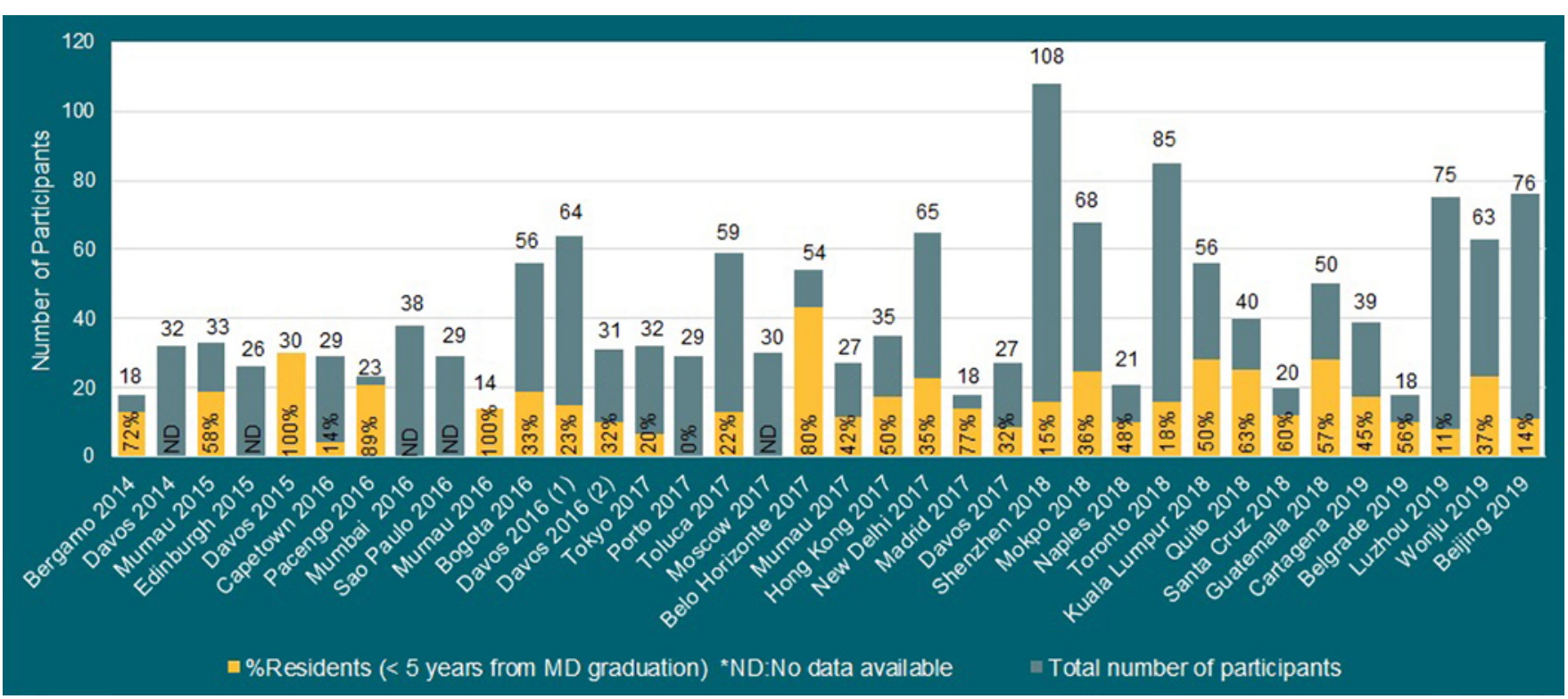

FIG. 2. Graph showing the number of participants in 36 neurotrauma CME activities worldwide.

Overall content average usefulness: $\mathbf{4 . 2}$

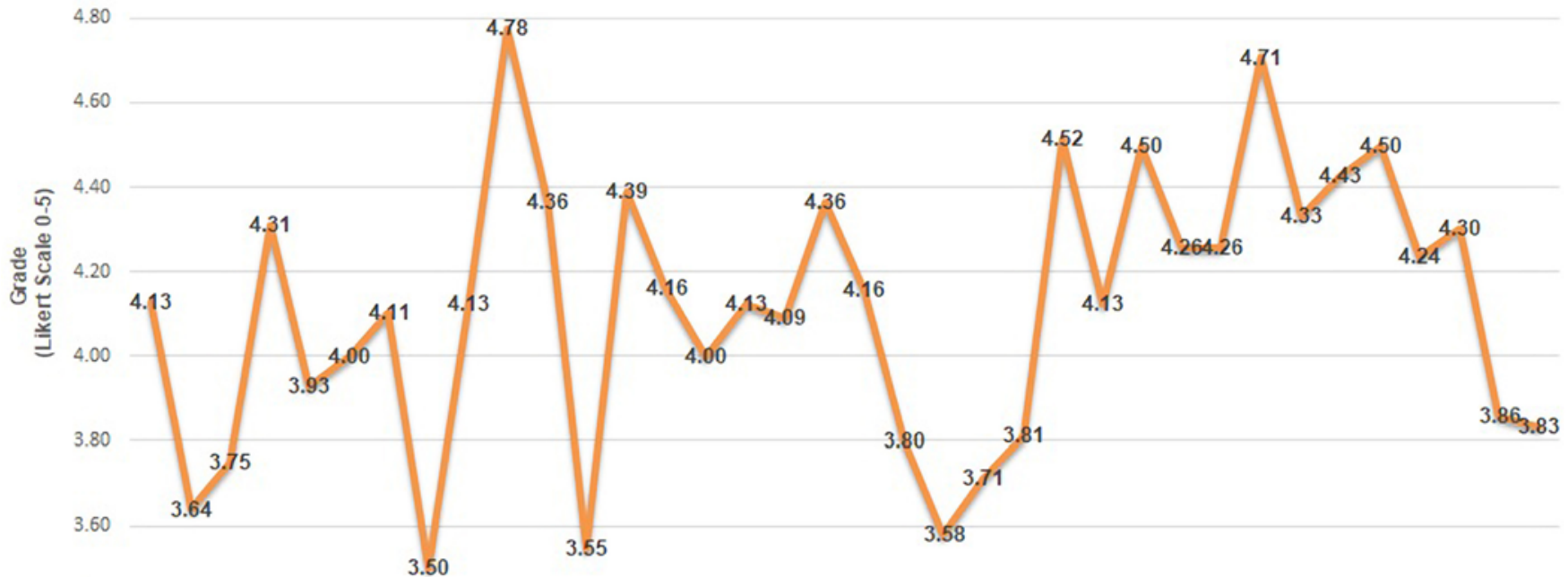

3.40

3.20

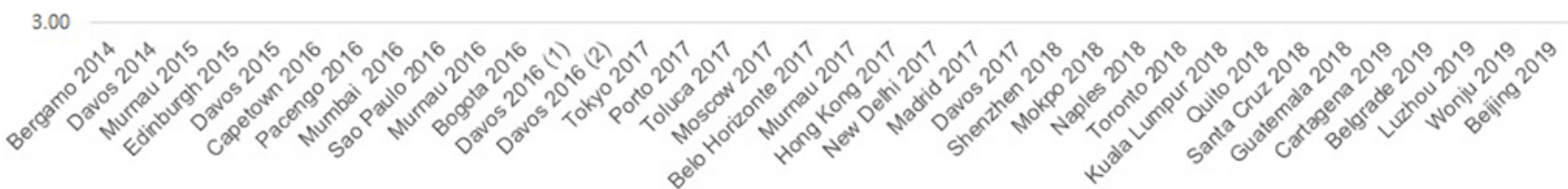

FIG. 3. Chart showing overall content usefulness and usability of neurotrauma CME activities in a Likert scale rating from 0 (no usefulness or usability in my daily practice) to 5 (very high usefulness and usability in my daily practice). 


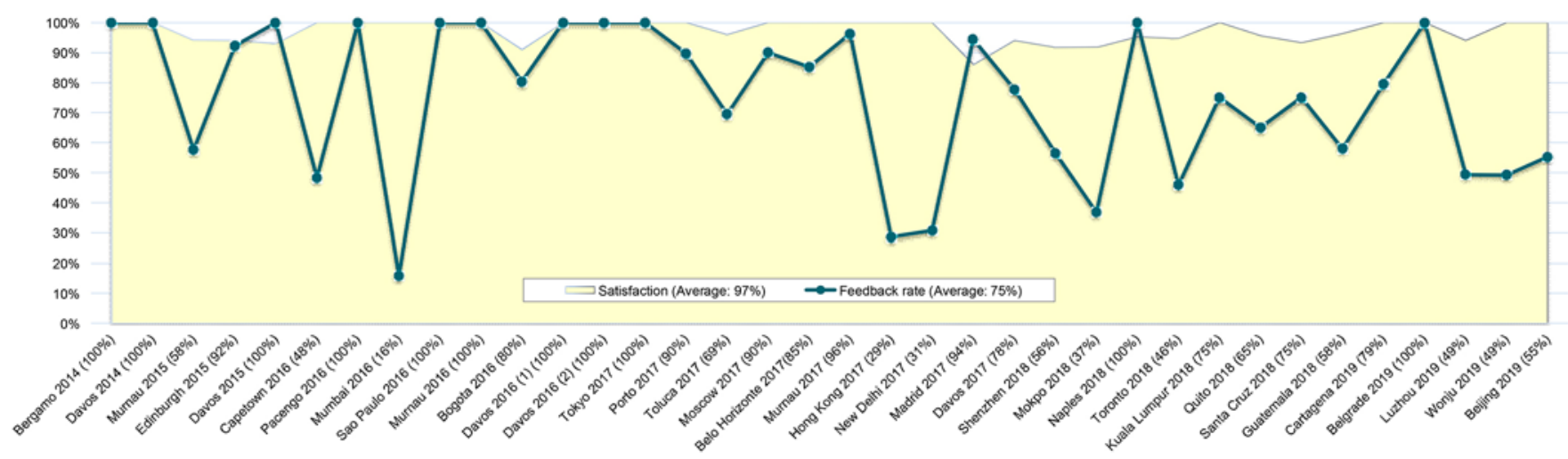

FIG. 4. Overall level of satisfaction with the neurotrauma CME activities worldwide.

garding the learning and teaching process in other areas of surgical specialties. ${ }^{2,10,13,14}$ The backward planning for the development of the course curriculum in neurotrauma is based on the methodology of successful previous experiences from the $\mathrm{AO}$ Foundation educational group and Canadian surgical academic groups, two of the most recognized academic entities in surgical education worldwide. ${ }^{6,16,34}$

The current neurotrauma course curriculum of the Global Neuro group covers aspects from the theoretical basis and practical principles to the management of complex cranial neurotrauma issues, including the use of advanced monitoring, devices, and techniques that are the foundation for managing cranial neurotrauma. An additional focus on current research and challenging clinical scenarios has been included recently in order to accomplish the applicability and transferability of knowledge concepts to different contexts in different regions of the world. ${ }^{1,3,34}$

The impact of competency-based education has been proved in different scenarios, from physical to virtual education. In order to frame the development of the actual and future course curriculum exercises for neurotrauma, it will be essential to take into account the concepts of global neurosurgery, including the neurotrauma procedures and the most common interventions performed by neurosurgical practitioners worldwide..$^{9,11,29}$ To address equipment limitations or limited experience in the field, the content of the course curriculum, in order to develop CME activities or future training programs, was divided into the following units: 1) essentials and 2) advanced concepts and interventions in neurotrauma care. This strategy has been used in worldwide-recognized successful educational activities from several surgical and critical care medical societies. ${ }^{4,5,30}$

The course curriculum is focused on the prevention of morbidity; nevertheless, it provides more in-depth knowledge in the advanced course event, also concentrating efforts in complex procedures, which require advanced surgical equipment or more experience. The delivery of the surgical skills concepts using simulation models is highlighted, knowing that simulation is essential for learning and maintaining postgraduate surgical skills. These concepts have been widely validated over the years in different regions of the world. ${ }^{17,18,21}$
Additional competencies in professionalism and communication skills aspects have been considered as an essential part of the course curriculum, understanding the impact of these skills, knowledge concepts, and attitudes when facing difficult cases and decision-making points in the care of severe TBI even in high- or low-resource settings. These elements of the training process have been recognized as pivotal aspects and desired skills for actual and future neurotrauma providers around the world. ${ }^{12,33} \mathrm{In}$ the evaluation component, the feedback from the learner is crucial, and this strategy was applied during the testing courses to 1583 participants.

\section{Future Opportunities and Application to Other Areas}

The course curriculum assessment of each of the CME events was crucial in order to improve and complement the competency-based proposal. It is undoubtedly essential to understand that these kinds of educational programs can improve the competencies and abilities of the participants through knowledge and skills building even after graduation, going further than traditional online models of CME ${ }^{27,28,29}$ It is crucial also to recognize the usefulness of the course curriculum to be applied for the enhancement of the actual tracks of formal training programs in different regions of the world.

These concepts integrated into the course curriculum fit very well into the so-called risk control and quality management in neurosurgery, an important concept when thinking about patient safety in a challenging and complex field like neurotrauma management. ${ }^{19}$

Finally, the high value of qualification and the percentage of acceptance among the participants can allow us to consider this curricular model as a successful experience and a unique opportunity for neurotrauma educators worldwide. This is a continuous process, and we still continuously evaluate the model in different educational activities all over the world, including activities in LMIC and high-income countries. We expect soon to evaluate the impact of the proposed course curriculum in programs like neurosurgical residency or neurotrauma fellowship programs in different regions of the world. We also expect to apply this process in other areas of neurosurgical practice, such as cerebrovascular or skull base surgery. 


\section{Conclusions}

An international competency-based course curriculum, developed by academic neurotrauma experts, can create a well-accepted neurotrauma educational process designed to address a broad spectrum of the needs that a neurotrauma practitioner faces during the basic or advanced care of these patients in different regions of the world. This process may be applied to other areas of neurosurgical knowledge, such as cerebrovascular or skull base surgery. Moreover, this process allows worldwide standardization of the knowledge requirements and competencies, such that training may be better benchmarked between countries and areas, regardless of their income level.

\section{Acknowledgments}

Special thanks to the members of the Global Neuro Foundation Neurotrauma Curriculum Committees who have been participating in the process: Dr. Christian Matula, Dr. Aurelia Peraud, Dr. Francesco Biroli, Dr. José Fernández-Alén, Dr. Michael Bierschneider, Dr. Gregory Hawryluk, Dr. Maya Babu, Dr. Ross Bullock, Dr. Andrés Rubiano, and Michael Cunningham; and to the Global Neuro Foundation Board and the administrative office, including Dr. Paul Manson, Linda Domeisen, Dr. Tobias Hüttl, Prattipati Laxminarain, Tamara Schoenauer, Ximena Rodriguez, and Frédérique Wiemeijer. Additional thanks to the peer reviewers of the Global Neuro Neurotrauma Curriculum Document, including Drs. Rocco Armonda and Stephen Lewis.

Thanks to the National Institute for Health Research (NIHR) Global Health Research Group in Neurotrauma of the University of Cambridge, which is supporting the academic activities of the corresponding author, Dr. Rubiano.

\section{References}

1. Anderson GA, Kayima P, Ilcisin L, Benitez NP, Albutt KH, Briggs SM, et al: Development of a comprehensive trauma training curriculum for the resource-limited environment. J Surg Educ 75:1317-1324, 2018

2. Androulakis J, Stavropoulos MN: Education in the management of trauma patients (ATLS-PHTLS). Arch Hellen Med 19:333-344, 2002

3. Asthagiri A: Instructions for obtaining SANS Neurosurgery Continuing Medical Education (CME) credit. Neurosurgery 75:N9, 2014

4. Bouillon B, Kanz KG, Lackner CK, Mutschler W, Sturm J: [The importance of Advanced Trauma Life Support (ATLS) in the emergency room.] Unfallchirurg 107:844-850, 2004 (German)

5. Corley J, Lepard J, Barthélemy E, Ashby JL, Park KB: Essential neurosurgical workforce needed to address neurotrauma in low- and middle-income countries. World Neurosurg 123:295-299, 2019

6. Crow ML, Pant MD: Twenty-six years of changes in education students' attitudes. J Educ Social Policy 2:13-29, 2015

7. Davis J, Crabb S, Rogers E, Zamora J, Khan K: Computerbased teaching is as good as face to face lecture-based teaching of evidence based medicine: a randomized controlled trial. Med Teach 30:302-307, 2008

8. Deptula P, Chun MB: A literature review of professionalism in surgical education: suggested components for development of a curriculum. J Surg Educ 70:408-422, 2013

9. Dewan MC, Rattani A, Baticulon RE, Faruque S, Johnson WD, Dempsey RJ, et al: Operative and consultative proportions of neurosurgical disease worldwide: estimation from the surgeon perspective. J Neurosurg 130:1098-1106, 2019

10. Dewan MC, Rattani A, Fieggen G, Arraez MA, Servadei F,
Boop FA, et al: Global neurosurgery: the current capacity and deficit in the provision of essential neurosurgical care. J Neurosurg 130:1055-1064, 2019

11. Dewan MC, Rattani A, Gupta S, Baticulon RE, Hung YC, Punchak M, et al: Estimating the global incidence of traumatic brain injury. J Neurosurg 130:1080-1097, 2019

12. Doyle-Scharff M: AO principles of teaching and learning. $\mathbf{J}$ Contin Educ Health Prof 25:297, 2005

13. Fontes RB, Selden NR, Byrne RW: Fostering and assessing professionalism and communication skills in neurosurgical education. J Surg Educ 71:e83-e89, 2014

14. Gasco J: Present and future of neurosurgery training and education. Malays J Med Sci 21:1-3, 2014

15. Gélinas-Phaneuf N, Del Maestro RF: Surgical expertise in neurosurgery: integrating theory into practice. Neurosurgery 73 (Suppl 1):30-38, 2013

16. Green JS, de Boer PG: AO Principles of Teaching and Learning. New York: Thieme, 2005

17. Horton R: GBD 2010: understanding disease, injury, and risk. Lancet 380:2053-2054, 2012

18. Kolias AG, Rubiano AM, Figaji A, Servadei F, Hutchinson PJ: Traumatic brain injury: global collaboration for a global challenge. Lancet Neurol 18:136-137, 2019

19. Konakondla S, Fong R, Schirmer CM: Simulation training in neurosurgery: advances in education and practice. Adv Med Educ Pract 8:465-473, 2017

20. Larouche J, Yee AJ, Wadey V, Ahn H, Hedden DM, Hall $\mathrm{H}$, et al: Development of a competence-based spine surgery fellowship curriculum set of learning objectives in Canada. Spine (Phila Pa 1976) 41:530-537, 2016

21. Lobato RD, Jiménez Roldan L, Alen JF, Castaño AM, Munarriz PM, Cepeda S, et al: [Competency-based neurosurgery residency programme.] Neurocirugia (Astur) 27:75-86, 2016 (Spanish)

22. Moore DE Jr, Green JS, Gallis HA: Achieving desired results and improved outcomes: integrating planning and assessment throughout learning activities. J Contin Educ Health Prof 29:1-15, 2009

23. Oliveira LM, Figueiredo EG: Simulation training methods in neurological surgery. Asian J Neurosurg 14:364-370, 2019

24. Peeters W, van den Brande R, Polinder S, Brazinova A, Steyerberg EW, Lingsma HF, et al: Epidemiology of traumatic brain injury in Europe. Acta Neurochir (Wien) 157:16831696,2015

25. Roberts L, Cornell C, Bostrom M, Goldsmith S, Ologhobo $\mathrm{T}$, Roberts T, et al: Communication skills training for surgical residents: learning to relate to the needs of older adults. J Surg Educ 75:1180-1187, 2018

26. Roozenbeek B, Maas AI, Menon DK: Changing patterns in the epidemiology of traumatic brain injury. Nat Rev Neurol 9:231-236, 2013

27. Rosseau G, Johnson WD, Park KB, Arráez Sánchez M, Servadei F, Vaughan KA: Global neurosurgery: current and potential impact of neurosurgeons at the World Health Organization and the World Health Assembly. Executive summary of the World Federation of Neurosurgical Societies-World Health Organization Liaison Committee at the 71st World Health Assembly. Neurosurg Focus 45(4):E18, 2018

28. Rubiano AM, Carney N, Chesnut R, Puyana JC: Global neurotrauma research challenges and opportunities. Nature 527:S193-S197, 2015

29. Rubiano AM, Puyana JC, Mock CN, Bullock MR, Adelson PD: Strengthening neurotrauma care systems in low and middle income countries. Brain Inj 27:262-272, 2013

30. Shaye DA, Tollefson T, Shah I, Krishnan G, Matic D, Figari M, et al: Backward planning a craniomaxillofacial trauma curriculum for the surgical workforce in low-resource settings. World J Surg 42:3514-3519, 2018

31. Steiger HJ: Risk control and quality management in neu- 
rosurgery. Munich October 15-18, 2000. Acta Neurochir (Wien) 143:100-102, 2001

32. Suri A, Patra DP, Meena RK: Simulation in neurosurgery: past, present, and future. Neurol India 64:387-395, 2016

33. Ten Cate O: Competency-based postgraduate medical education: past, present and future. GMS J Med Educ 34:Doc69, 2017

34. World Health Organization: Injuries and violence: the facts. WHO. (https://www.who.int/violence_injury_prevention/ key_facts/en/) [Accessed January 14, 2020]

\section{Disclosures}

The AO Foundation supported the initiation of this curricular development process. Global Neuro supports the final part of the curricular development process. Dr. Calero-Martinez claims no conflict of interest; the rest of the authors are active members of the Global Neuro Curriculum Committee.

\section{Author Contributions}

Conception and design: Rubiano, Matula, Peraud, Biroli, Fernández-Alén, Bierschneider, Cunningham, Hawryluk, Babu, Bullock. Acquisition of data: Rubiano, Calero-Martinez. Analysis and interpretation of data: Rubiano, Calero-Martinez. Drafting the article: Rubiano, Calero-Martinez, Biroli, Fernández-Alén, Hawryluk, Bullock. Critically revising the article: Rubiano, Calero-Martinez, Matula, Peraud, Biroli, Fernández-Alén, Bierschneider, Hawryluk, Babu, Bullock. Reviewed submitted version of manuscript: all authors. Approved the final version of the manuscript on behalf of all authors: Rubiano.

\section{Supplemental Information}

Online-Only Content

Supplemental material is available online. AONeuro Curricula. https://thejns.org/doi/suppl/10.3171/2019. 12.FOCUS19850.

\section{Correspondence}

Andrés M. Rubiano: Meditech Foundation, Santiago de Cali, Colombia. andresrubiano@aol.com. 